\title{
Terminologie vir Drywingselektronika (Deel III) Tiristorterminologie
}

\author{
C.G. Steyn en J.D. van Wyk \\ Fakulteit Ingenieurswese, Randse Afrikaanse Universiteit, Posbus 524, Johannesburg
}

Meegaande terminologie is 'n vervolg op die reeds gepubliseerde deel I en II van die terminologie vir Drywingselektronika., 2 Slegs die meer algemene terme vir tiristors word hier behandel. In toekomstige bydraes sal aandag geskenk word aan die beskrywing, klassifikasie en simboliese voorstelling van tiristors. Daar is sover moontlik gepoog om die voorskrifte van die Internasionale Elektrotegniese Kommissie $^{3,4,5}$ na te volg. Lesers se kommentaar op enige aspek van die drywingselektronikaterminologie sal verwelkom word. Die benaming tiristor word hier gebruik vir 'n simmetriese tiristor (sperrende triodetiristor).

\section{HOOFKLEMME}

Die twee klemme waardeur die hoofstroom vloei.

\section{ANODEKLEM (A)}

Die klem waarheen (konvensionele) stroom vanaf die eksterne stroombaan vloei wanneer die tiristor in die geleitoestand verkeer.

\section{KATODEKLEM (K)}

Die klem waarvandaan stroom na die eksterne stroombaan vloei wanneer die tiristor in die geleitoestand verkeer.

\section{HEKKLEM (G)}

Klem waardeur slegs beheerstroom v!oei.

\section{AANTOESTAND, GELEITOESTAND, GELEIDINGSTOESTAND}

Toestand van 'n tiristor wat ooreenstem met die lae-weerstand-, lae-spanningsgedeelte van die stroom-spanningkarakteristiek van die tiristor.

\section{BLOKKEERTOESTAND}

Nie-geleidende toestand waarin 'n tiristor verkeer tussen die oorsprong en die wippunt, op die voorwaartse stroom-spanningkarakteristiek.

\section{SPERTOESTAND}

Toestand waarin 'n tiristor verkeer tussen die oorsprong en die deurbreekspanning, waar die trustroom baie kleiner is as die trustroom by die deurbraakpunt.

\section{HOOFSPANNING, HOOFKLEMSPANNING, ANODE-KATODESPANNING $u_{A K}$}

Spanning (potensiaalverskil) tussen die hoofklemme. Dit is positief indien die anode by 'n hoër potensiaal as die katode is en negatief indien die anodepotensiaal laer is as die katodepotensiaal.

\section{HOOFSTROOM, HOOFKLEMSTROOM, ANODE-KATODESTROOM $i_{\text {AK }}$}

Stroom wat deur die hoofklemme vloei. Dit is positief indien die stroom intern vanaf die anode na die katode vloei. 


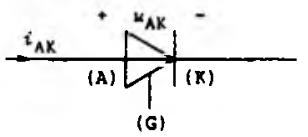

(a)

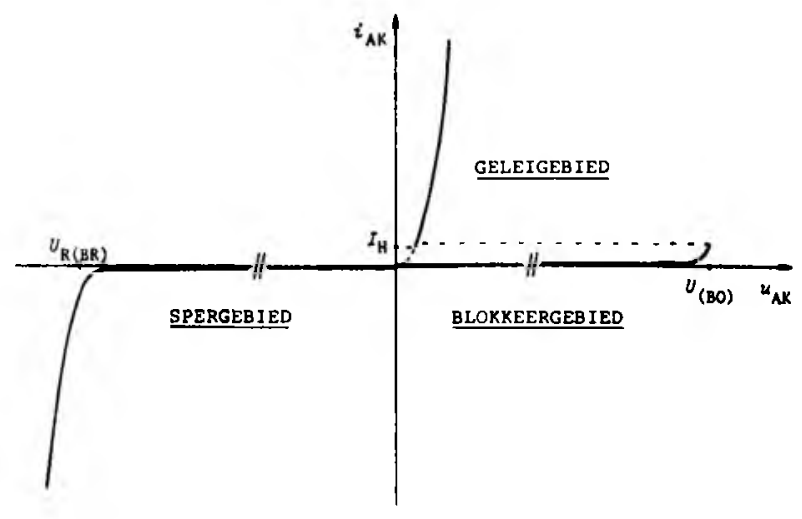

(b)

FIGUUR 1: Simmetriese Tiristor:

(a) Skematiese voorstelling (algemene Tiristor);

(b) Stroom-spanningkarakteristiek.

\section{AANSKAKEIING}

Proses waartydens die tiristor vanaf die blokkeerna die geleitoestand geskakel word. Indien die skakelproses geskied a.g.v. die aanwending van 'n hekstuurpuls, kan dit ook ontsteking genoem word.

\section{AFSKAKELING, DOWING}

Proses waartydens die tiristor van die geleitoestand na die sper- of blokkeertoestand geskakel word.

\section{AANSPANNING, GELEISPANNING $u_{\mathrm{T}}, U_{\mathrm{T}}$}

Hoofklemspanning (anode-katodespanning) van die tiristor wanneer dit in die geleitoestand is $\left(u_{T}\right.$ oomblikswaarde, $U_{\mathrm{T}}$ konstante waarde).

\section{AANSTROOM $i_{\mathrm{T}}, I_{\mathrm{T}}$}

Die hoofstroom wat deur die tiristor vloei wanneer dit in die geleitoestand is $\left(i_{\mathrm{T}}\right.$ oomblikswaarde, $I_{\mathrm{T}}$ konst ante waarde).

\section{(GEMIDDELLDE A ANSTROOM $I_{\text {T(Rem) }}$}

Gemiddelde waarde van die aanstroom, geneem oor 'n volle siklus.

\section{EFFEKTIEWE AANSTROOM $\boldsymbol{I}_{\text {Teff }}$}

Effektiewe waarde van die aanstroom, bereken vanuit die wortel van die gemiddelde kwadraat van die stroom.

\section{BEGIN-AANSTROOM $I_{\text {Tb }}$}

Aanvanklike waarde van die aanstroom, oorgangsverskynsels nagelaat. (Sien figuur 5 .)

\section{EINI)-AANSTROOM $\boldsymbol{I}_{\text {Te }}$}

Finale waarde van die aanstroom, d.w.s. net voor afskakeling begin. (Sien figuur 5 .)
PIEKAANSTROOM $I_{\text {TRM }}$

Maksimum oomblikswaarde van die aanstroom, insluitend alle herhaalde oorgangstrome.

\section{ENKELPIEKAANSTROOM $\boldsymbol{I}_{\text {TSM }}$}

Nie-herhaalde voorwaartse stroom wat tot gevolg sal hê dat die maksimụm ontwerpvlaktemperatuur oorskry sal word. Daar word egter veronderstel dat sulke pieke selde gedurende die tiristor se leeftyd sal voorkom en dan alleen as gevolg van abnormale omstandighede (byvoorbeeld gedurende fouttoestande).

\section{OORSTROOM, VOORWAARTSE OORSTROOM $I_{\text {T(OV) }}$}

Kontinue toepassing van dié voorwaartse stroom sal tot gevolg hê dat die maksimum toelaatbare vlaktemperatuur oorskry word, maar die tydsduur word so beperk dat hierdie temperatuur nie oorskry word nie.

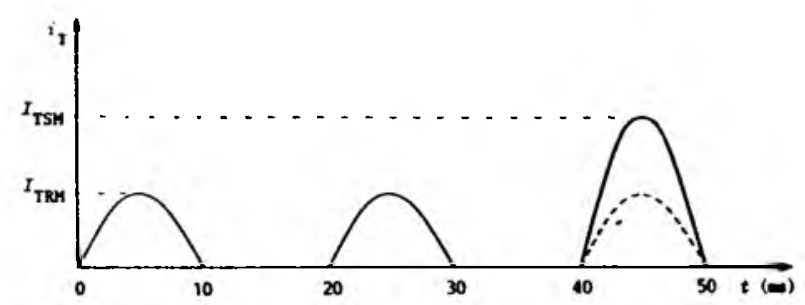

FIGUUR 2: Tiristorstrome.

\section{BLOKKEERSPANNING $u_{\mathrm{D}}, U_{\mathrm{D}}$}

Positiewe anode-katodespanning oor die tiristor wanneer dit in die blokkeertoestand is $\left(u_{\mathrm{D}}\right.$ oomblikswaarde, $U_{\mathrm{D}}$ konstante waarde).

\section{WIPSPANNING $\boldsymbol{U}_{(\mathrm{BO})}$}

Spanning by die wippunt.

\section{WIPPUNT}

Dié punt op die voorwaartse spanning-stroomkarakteristiek waar die differensiële weerstand nul is en die anode-katodespanning 'n maksimum waarde bereik.

\section{KRUINBLOKKEERSPANNING $\boldsymbol{U}_{\text {DWM }}$}

Hoogste oomblikswaarde van die blokkeerspanning wat oor 'n tiristor voorkom, uitsluitend alle herhaalde en nie-herhaalde oorgangspannings.

\section{PIEKBL.OKKEERSPANNING $\boldsymbol{U}_{\mathrm{DRM}}$}

Hoogste oomblikswaarde van die blokeerspanning wat oor 'n tiristor voorkom, insluitend alle herhaalde oorgangspannings, maar uitsluitend alle nie-herhaalde oorgangspannings.

\section{ENKELPIEKBLOKKEERSPANNING $\boldsymbol{U}_{\text {IDM }}$}

Hoogste oomblikswaarde van enige nie-herhaalde blokkeerspanning wat oor 'n tiristor voorkom.

\section{SPERSPANNING $u_{R}, U_{R}$}

Negatiewe anode-katodespanning, met ander woorde, 'n truspanning $\left(u_{\mathrm{R}}\right.$ oomblikswaarde, $U_{\mathrm{R}}$ konstante waarde). 


\section{DEURBREEKSPANNING,}

\section{DEURBRAAKSPANNING $U_{\mathrm{R}(\mathrm{BR})}$}

Waarde van die negatiewe anode-katodespanning (sperspanning), waar die differensiële weerstand tussen die hoofklemme van 'n hoë na 'n lae waarde verander.

\section{KRUINSPERSPANNING $U_{\text {RWM }}$}

Hoogste oomblikswaarde van die sperspanning wat oor 'n tiristor voorkom, insluitend alle herhaalde, maar uitsluitend alle nie-herhaalde oorgangspannings.

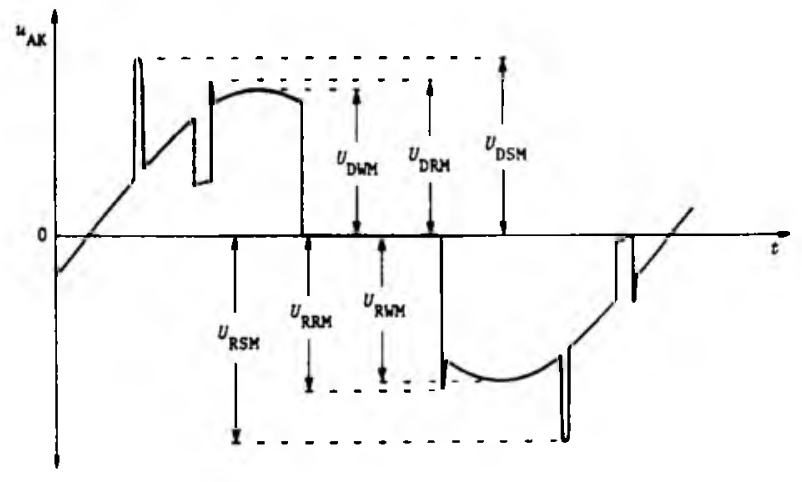

FIGUUR 3: Tiristorspannings.

\section{ENKELPIEKSPERSPANNING $\boldsymbol{U}_{\text {RSM }}$}

Hoogste oomblikswaarde van enige nie-herhaalde sperspanning wat oor 'n tiristor voorkom.

\section{DRUMPELSPANNING, DREMPELSPANNING $U_{(\text {TO) }}$}

Waarde van die spanning wat verkry word by die snyding van die spanning-as en die reguitlyn wat die karakteristiek van die tiristor in die geleidingsgebied benader. (Sien figuur 4 .)

\section{AANWELRSTAND $r_{T}$}

Waarde van die omgekeerde van die helling van die reguit lyn soos gebruik vir die bepaling van die drumpelspanning.

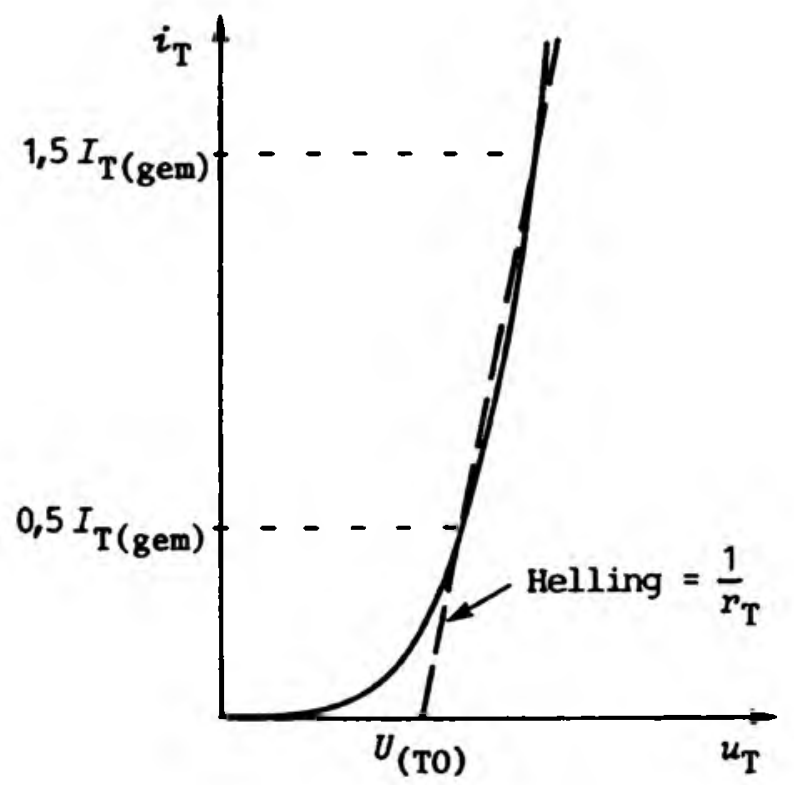

FIGUUR 4: Tiristor se geleikarakteristiek.

\section{HOUSTROOM $I_{\mathrm{H}}$}

Minimum waarde van die voorwaartse hoofstroom wat nodig is om die tiristor in die geleitoestand te hou.

\section{GRENDELSTROOM, SLUITSTROOM $I_{L}$}

Minimum waarde van die voorwaartse hoofstroom wat bereik moet wees teen die einde van die hekstroompuls, wanneer die tiristor van die blokkeer- na die geleitoestand geskakel word, sodat die tiristor in die geleitoestand sal bly.

\section{KRITIESE TEMPO VAN STROOMTOENAME $\frac{\mathrm{d} i_{1}}{\mathrm{~d} t}$ (krit)}

Hoogste waarde van toenemende stroomverandering met tyd wat die tiristor kan weerstaan sonder om enige nadelige uitwerking te ondervind.

\section{KRITIESE TEMPO VAN SPANNINGSTOENAME $\frac{\mathrm{d} u_{\mathrm{D}}}{\mathrm{d} t}$ (krit)}

Laagste waarde van toenemende spanningsverandering met tyd wat sal veroorsaak dat die tiristor van die blokkeer- na die geleitoestand sal skakel, onder gespesifiseerde toestande.

\section{GELEIDINGSVERLIES, AANVERLIES $p_{\mathrm{T}}, \boldsymbol{P}_{\mathrm{T}}$}

Drywingsverlies a.g.v. die vloei van voorwaartse stroom tydens geleiding ( $p_{\mathrm{T}}$ oombliksdrywing, $\boldsymbol{P}_{\mathrm{T}}$ gemiddelde drywing). Indien $u_{\top}$ en $i_{\top}$ die oomblikswaarde van aanspanning en -stroom is en $T$ die herhalingsperiode, word die geleidingsverlies soos volg uitgedruk: $P_{\mathrm{T}}=\frac{1}{T_{0}} \int^{T} p_{\mathrm{T}} \mathrm{d} t=\frac{1}{T} \int_{0} \int^{T} u_{\mathrm{T}} \cdot i_{\mathrm{T}} \mathrm{d} t$

\section{BLOKKEERLEKSTROOM $i_{\mathrm{p}}, I_{\mathrm{p}}$}

Voorwaartse (lek-)stroom wanneer die tiristor in die blokkeertoestand is ( $i_{\mathrm{D}}$ oomblikswaarde, $I_{\mathrm{D}}$ konstante vaarde).

\section{TRUSTROOM $i_{\mathrm{R}}, \boldsymbol{I}_{\mathrm{R}}$}

Stroom wat deur die tiristor in die trurigting vloei, d.w.s. negatiewe anode-katodestroom $\left(i_{\mathrm{R}}\right.$ oomblikswaarde, $I_{\mathrm{R}}$ konstante waarde).

\section{PIEKSTRUSTROOM $\boldsymbol{I}_{\mathrm{RM}}$}

Maksimum waarde van die trustroom tydens die - trustroomtyd.

\section{TRUSTROOMTYD $t_{\pi}$}

Tyd wanneer die trustroom deur die tiristor vloei tydens oorskakeling van die gelei- na die spertoestand. Dit word gedefinieer as die tyd vandat die trustroom begin vloei, totdat dit afgeneem het na $10 \%$ van die piektrustroomwaarde $I_{R M}$. Sien figuur 5 . (Vergelyk ook die definisie vir 'n diode.)

\section{TRUSTROOMVALTYD $t_{\mathbf{r}}$}

Tydsduur waartydens die trustroom afneem van die maksimum waarde $I_{\mathrm{RM}}$, na $10 \%$ van $I_{\mathrm{RM}}$. 


\section{STOORLADING, GESTOORDE LADING $Q_{\text {s }}$}

Lading wat in 'n tiristor gestoor word gedurende geleiding. Dit is gelyk aan die produk van die voorwaartse stroom en die minderheidsdraerleeftyd in die halfgeleier. $Q_{\mathrm{s}}=I_{\mathrm{Te}} \cdot \tau$.

\section{HERWONNE LADING $Q_{\boldsymbol{r}}$}

Lading wat deur die eksterne stroombaan uit die tiristor verwyder word gedurende die trustroomtyd. Dit is die tydsintegraal van die trustroom en word gedefinieer as die oppervlakte van die gearseerde gebied in figuur 5 . Indien herkombinasie nagelaat word, is die herwonne lading gelyk aan die gestoorde lading. Die herwonne lading is 'n funksie van gestoorde lading, tempo van stroomafname, draerleeftyd (herkombinasie) en vlaktemperatuur.

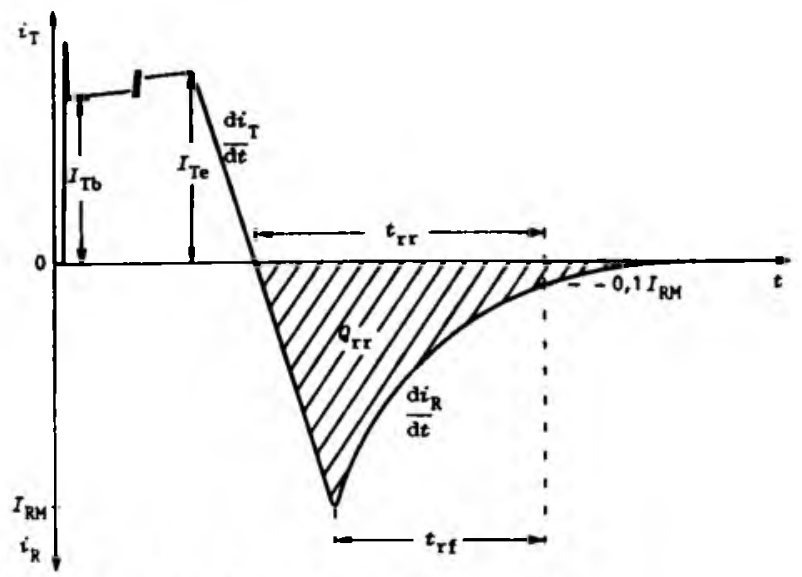

FIGUUR 5: Afskakelkarakteristiek.

\section{VRYWORDTYD $t$,}

Tydsverloop tydens afskakeling waartydens die oortollige minderheidsdraers in die middelste oorstroomde gebied verdwyn a.g.v. herkombinasie.

\section{RUSTYD $t_{\mathrm{s}}$}

Tydsverloop tydens afskakeling vandat die hoofstroom deur die tiristor na nul afgeneem het, totdat 'n blokkeerspanning oor die tiristor aangelê word, sonder dat die tiristor weer aanskakel, onder gespesifiseerde toestande. Sien figuur 6 .

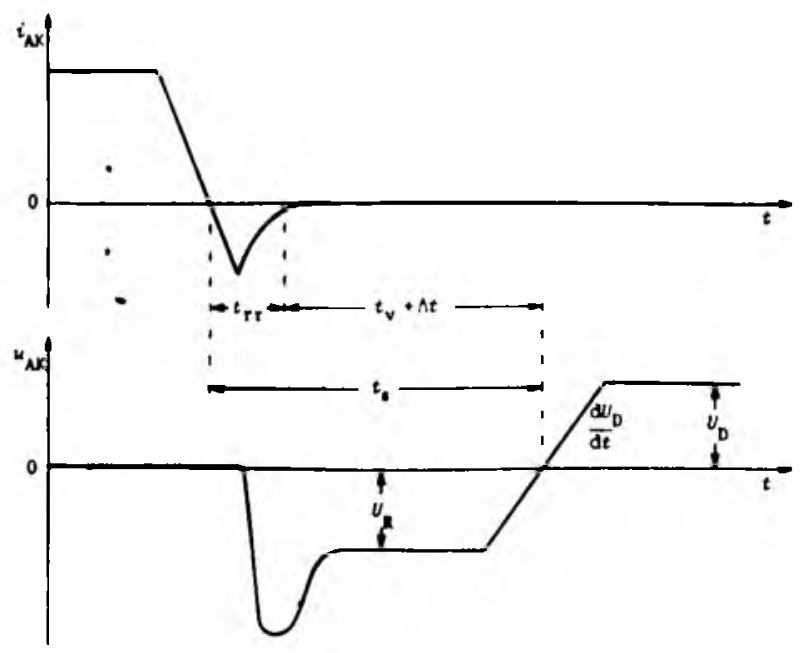

FIGUUR 6: Rustyd van 'n Tiristor.
HERSTELTYD $t_{q}$

Die hersteltyd is die minimum waarde van die rustyd. $t_{\mathrm{q}}=t_{\mathrm{s}}(\mathrm{min})=t_{\mathrm{rr}}+t_{\mathrm{v}}$.

HEKSTROOM $i_{\mathrm{G}}, \boldsymbol{I}_{\mathrm{G}}$

Stroom wat aan die hekklemme gelewer word $\left(i_{\mathrm{G}}\right.$ oomblikswaarde, $I_{\mathrm{G}}$ konstante waarde).

\section{VOORWAARTSE HEKSTROOM $I_{\mathrm{GF}}$}

Hekstroom verbind met 'n voorwaartse hekspanning.

PEIK.VOORW AARTSE HEKSTROOM $\boldsymbol{I}_{\text {GFM }}$

Hoogste oomblikswaarde van voorwaartse hekstroom.

\section{HEKTRUSTROOM $\boldsymbol{I}_{\text {GR }}$}

Hekstroom verbind met die hektruspanning.

\section{HEKSTUURSTROOM $\boldsymbol{I}_{\text {GT }}$}

Minimum hekstroom benodig om 'n tiristor van die blokkeer- na die geleitoestand te skakel, onder gespesifiseerde toestande.

\section{MAKSIMUM HEKSTEURSTROOM $\boldsymbol{I}_{\text {GD }}$}

Grootste hekstroom wat nie sal veroorsaak dat 'n tiristor van die blokkeer- na die geleitoestand skakel nie.

HEKSPANNING $u_{G}, U_{G}$

Spanning tussen die hek en 'n gespesifiseerde hoofklem ( $u_{\mathrm{G}}$ oomblikswaarde, $U_{\mathrm{G}}$ konstante waarde).

\section{VOORWAARTSE HEKSPANNING $U_{G r}$}

Positiewe hek-katodespanning vir tiristors met P-tipe hekke. Negatiewe hek-anodespanning vir tiristors met $\mathrm{N}$-tipe hekke.

\section{PIEK-VOORW AARTSE HEKSPANYING $\boldsymbol{U}_{\text {Gir }}$}

Hoogste oomblikswaarde van voorwaartse hekspanning, insluitend alle oorgangspannings.

\section{HEKTRUSPANNING $U_{\text {GR }}$}

Negatiewe hek-katodespanning vir tiristors met P-tipe hekke. Positiewe hek-anodespanning vir tiristors met N-tipe hekke.

\section{PIEKHEKTRUSPANNING $\boldsymbol{U}_{\text {GRM }}$}

Hoogste waarde van hektruspanning, insluitend alle oorgangspannings.

\section{HEKSTUURSPANNING $U_{G T}$}

Hekspanning benodig om die hekstuurstroom te veroorsaak.

\section{MAKSIMLM HEKSTEURSPANNING $U_{G D}$}

Hoogste hekspanning wat nie sal veroorsaak dat 'n tiristor van die blokkeer- na die geleitoestand skakel nie. 
na die geleitoestand skakel a.g.v. die toepassing van 'n hekstuurpuls. Dit word gemeet vanaf 'n spesifieke punt aan die begin van die hekstroompuls (10\% van $I_{\mathrm{GT}}$ ) totdat die voorwaartse spanning oor die tiristor van die aanvanklike waarde $U_{\mathrm{D}(\mathrm{af})}$ na 'n spesifieke waarde ( $10 \%$ van $\left.U_{\mathrm{D}(\mathrm{af})}\right)$ geval het. Die hekgestuurde aanskakeltyd is die som van die hekgestuurde vertraagtyd en -spanningsvaltyd. Sien figuur 7 . Indien dit nie tot verwarring kan lei nie, kan net van die aanskakeltyd gepraat word.

\section{HEKGESTUURDE VERTRAAGTYD, VERTRAAGTYD $t_{\mathrm{d}}$}

Tydsduur vanaf ' $n$ spesifieke punt aan die begin van die hekstroompuls, (10\% van $\left.I_{\mathrm{GT}}\right)$ totdat die voorwaartse spanning oor die tiristor tot 'n spesifieke waarde ná aan die aanvanklike waarde $(90 \%$ van $U_{\mathrm{D}(\mathrm{af})}$ ) afgeneem het, tydens die aanskakeling van 'n tiristor d.m.v. 'n hekstuurpuls.

\section{HEKGESTUURDE SPANNINGSVALTYD, SPANNINGSVALTYD $t_{\mathrm{fv}}$}

Tydsduur tussen die oomblik dat die voorwaartse spanning oor die tiristor afgeneem het vanaf 'n spesifieke waarde $\left(90 \%\right.$ van $\left.U_{\mathrm{D}(\mathrm{a})}\right)$ en die oomblik dat dit ' $n$ spesifieke lae waarde bereik het (10\% van $\left.U_{\mathrm{D}(\mathrm{an})}\right)$, tydens die aanskakeling van 'n tiristor d.m.v. 'n hekstuurpuls.

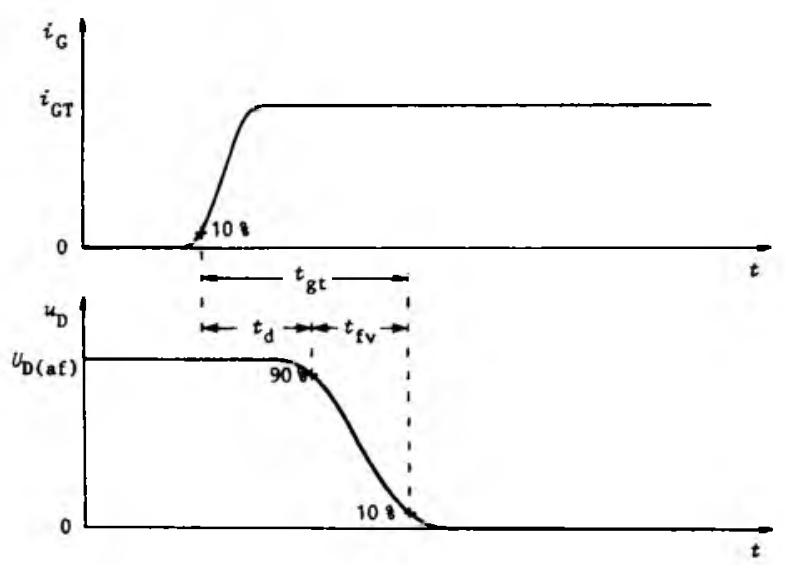

FIGUUR 7: Hekgestuurde skakeltye.

\section{$I^{2} t$-WAARDE}

'n Maatstaf vir die maksimum nie-herhaalde voorwaartse oorstroomkapasiteit vir 'n kort tydsduur. Die waarde is slegs geldig vir 'n gespesifiseerde tydsduur, (gewoonlik $10 \mathrm{~ms}$ ) met I die effektiewe stroom in ampere en $t$ die tydsduur in sekondes. Hierdie waarde word gebruik by die keuse van 'n geskikte sekering ter beskerming van die tiristor.

\section{SKYN-VLAKTEMPERATUUR $\boldsymbol{T}_{\mathrm{j}}$}

Hipotetiese temperatuur in die halfgeleiermateriaal wat gebaseer word op ' $n$ vereenvoudigde voorstelling van die termiese en elektriese gedrag van die tiristor. Hierdie temperatuur is nie noodwendig die hoogste temperatuur in die tiristor nie.

\section{TERMIESE WEERSTAND $\boldsymbol{R}_{\boldsymbol{\theta}}$}

Kwosiënt van die temperatuurverskil tussen twee gespesifiseerde punte of gebiede en die hittevloeitempo tussen hierdie twee punte of gebiede onder termiese ewewigstoestande. Vir die meeste gevalle kan die hittevloeitempo geneem word as gelyk aan die drywingsdissipasie. Dus $R_{\theta(\mathrm{x}-\mathrm{y})}=\frac{T_{\mathrm{x}}-T_{\mathrm{y}}}{P}$

\section{TERMIESE OORGANGSIMPEDANSIE $Z_{\theta(t)}$}

Kwosiënt van:

a. die verandering in die temperatuurverskil, soos bereik aan die einde van 'n tydsinterval, tussen die vlaktemperatuur en die temperatuur by ' $n$ gespesifiseerde eksterne verwysingspunt; en

b. die trapfunksie-verandering in drywingsdissipasie by die begin van dieselfde tydsinterval wat die temperatuurverandering veroorsaak.

Kortweg gestel: $Z_{\left.\theta(t)(\mathrm{j}-\mathrm{x})\right|_{t_{\mathrm{p}}}}=\frac{\Delta\left(T_{\mathrm{i}}-T_{\mathrm{x}}\right)}{\Delta P}$

Onmiddellik vóór die begin van hierdie tydsinterval moet die temperatuurverandering konstant wees as funksie van tyd. Termiese oorgangsimpedansie word gegee as 'n funksie van die tydsinterval (pulsduur) $t_{\mathrm{p}}$. Indien dit nie tot verwarring kan lei nie, kan net van die termiese impedansie gepraat word.

\section{VERWYSINGS}

1. Van Wyk, J.D.: Steyn, C.G. (1982). Stelselterminologie vir mutators in die drywingselektronika, Suid-Afrikaanse Tydskrif vir Natuurwetenskap en Tegnologie, 1(1), 5-6.

2. Steyn, C.G.; Van Wyk, J.D. (1985). Drywingsdiodeterminologie, Suid-Afrikaanse Tydskrif vir Natuurwetenskap en Tegnologie, 4(1), 7-9.

3. International Electrotechnical Commission. (1973). Semiconductor convertors, Publication 146, Second edition, Geneva, Appendix B

4. International Electrotechnical Commission. (1982). International electrotechnical vocabulary, Publication 50, Chapter 551: Power electronics, Geneva.

5. International Electrotechnical Commission. (1983). IEC multilingual dictionary of electricity, Geneva.

6. Noble, P.G. (1979). Understanding thyristor and triac data, Electronic Components and Applications, 1(3), 164-180.

7. Suid-Afrikaanse Buro vir Standaarde. (1968). Elektrotegniese verklarende woordelys, Groep II: Statiese omsetters, (SABS 042-11-1968), Pretoria. 